\title{
DISSECTION OF TWO DISTINCT DEFENSE-RELATED RESPONSES TO AGAR OLIGOSACCHARIDES IN GRACILARIA CHILENSIS (RHODOPHYTA) AND GRACILARIA CONFERTA (RHODOPHYTA) ${ }^{1}$
}

\author{
Florian Weinberger ${ }^{2}$ \\ UMR 7139 CNRS, Station Biologique, Place Georges Teissier, F-29682 Roscoff Cedex, France \\ Patricia Leonardi, Alicia Miravalles \\ Departamento de Biología, Bioquímica y Farmacia, Universidad Nacional del Sur, San Juan 670, 8000 Bahía Blanca, Argentina \\ Juan A. Correa \\ Departamento de Ecología and Center for Advanced Studies in Ecology \& Biodiversity, Facultad de Ciencias Biológicas, \\ Pontificia Universidad Católica de Chile, Casilla 114-D, Santiago, Chile \\ Ulrich Lion \\ Max-Planck-Institut für Chemische Ökologie, Hans-Knöll-Str. 8, D-07745 Jena, Germany

\section{Bernard Kloareg and Philippe Potin} \\ UMR 7139 CNRS, Station Biologique, Place Georges Teissier, F-29682 Roscoff Cedex, France
}

The two agar-producing red algae, Gracilaria chilensis C. J. Bird, McLachlan \& E. C. Oliveira and Gracilaria conferta (Schousboe ex Montagne) Montagne, responded with hydrogen peroxide $\left(\mathrm{H}_{2} \mathrm{O}_{2}\right)$ release when agar oligosaccharides were added to the medium. In $G$. conferta, a transient release was observed, followed by a refractory state of $6 \mathrm{~h}$. This response was sensitive to chemical inhibitors of NADPH oxidase, protein kinases, protein phosphatases, and calcium translocation in the cell, whereas it was insensitive to inhibitors of metalloenzymes. Transmission electron microscopic observations of the $\mathrm{H}_{2} \mathrm{O}_{2}$-dependent formation of cerium peroxide from cerium chloride indicated oxygen activation at the plasma membrane of $G$. conferta. A putative system, consisting of a receptor specific to agar oligosaccharides and a plasma membranelocated NADPH oxidase, appears to be responsible for the release of $\mathrm{H}_{2} \mathrm{O}_{2}$ in G. conferta. Subcellular examination of $G$. chilensis showed that the $\mathrm{H}_{2} \mathrm{O}_{2}$ release was located in the cell wall. It was sensitive to inhibitors of metalloenzymes and flavoenzymes, and no refractory state was observed. The release was correlated with accumulation of an aldehyde in the algal medium, suggesting that an agar oligosaccharide oxidase is present in the apoplast of G. chilensis. The presence of this enzyme could also be demonstrated by polyacrylamide elec-

\footnotetext{
${ }^{1}$ Received 13 January 2005. Accepted 10 May 2005.

${ }^{2}$ Author for correspondence and present address: IFM-GEOMAR, Düsternbrooker Weg 20, 24105 Kiel, Germany. e-mail fweinberger@ ifm-geomar.de.
}

trophoresis under nondenaturating conditions and proven to be variable. Cultivation of $G$. chilensis at 16 to $17^{\circ} \mathrm{C}$ resulted in significantly stronger expression of agar oligosaccharide oxidase than cultivation at $12^{\circ} \mathrm{C}$, which indicates that the enzyme is used under conditions that generally favor microbial agar macerating activity.

Key index words: Gracilaria; NADPH oxidase; oligoagar; oligosaccharide; oxidase

Abbreviations: DPI, diphenylene-iodonium; KCN, potassium cyanide; MTT, (3-[4,5-dimethylthiazol2-yl]-2,5-diphenyltetrazolium bromide; $\mathrm{NaN}_{3}$, sodium azide; ROS, reactive oxygen species; SHAM, salicylhydroxamic acid

Specific cell wall-derived oligosaccharides are known to regulate growth, development, and defense responses in higher plants (Darvill et al. 1992, Aldington and Fry 1993, John et al. 1997, Braam 1999, Vorwerk et al. 2004). Examples of recognition of oligosaccharides have also been reported for marine algae. Agar oligosaccharides released from the cell wall matrix of Gracilaria conferta (Schousboe ex Montagne) Montagne control the abundance of agar degrading bacteria at the surface of this alga (Weinberger and Friedlander 2000). Similarly, alginate oligosaccharides from the cell wall matrix of kelp sporophytes play a key role during the induction of resistance against algal endophytes and bacteria in the brown algae Laminaria digitata and Macrocystis pyrifera, respectively (Küpper et al. 2002). 
In plant and metazoan innate immunity systems, one of the earliest defense responses is the so-called oxidative burst, a rapid production of reactive oxygen species (ROS) such as $\mathrm{H}_{2} \mathrm{O}_{2}$ (Lamb and Dixon 1997, Wojtaszek 1997, Bolwell 1999, Laloi et al. 2004). Reactive oxygen species generated in the oxidative burst orchestrate the synthesis of defense-related proteins and phytoalexins (Apostol et al. 1987, Levine et al. 1994, Orozco-Cárdenas et al. 2001), and an increasing number of observations indicate that the oxidative burst after oligosaccharide recognition also mediates host-pathogen interactions in marine algae. Both $G$. conferta (Weinberger et al. 1999, 2001) and L. digitata (Küpper et al. 2001) react with an oxidative burst to the presence of agar or alginate oligosaccharides, respectively. Moreover, generation of $\mathrm{H}_{2} \mathrm{O}_{2}$ was shown to constitute an essential component of the defense system of the red alga Chondrus crispus against the green algal endophyte A. operculata (Bouarab et al. 1999, Weinberger et al. 2002, 2005).

At least six different enzymatic sources of ROS have been identified so far in algal and plant defense systems. Apoplastic L-amino acid oxidase plays a role for the resistance of $C$. crispus toward $A$. operculata (Weinberger et al. 2002), whereas pH-dependent apoplastic peroxidase (Bolwell et al. 1998, Martinez et al. 1998), apoplastic carbohydrate oxidase (Custers et al. 2004), apoplastic copper amine oxidase (Rea et al. 2002), and apoplastic oxalate oxidase (Zhang et al. 1995) have been reported from spermatophytes. A membrane-located NADPH oxidase complex can be activated through defense elicitation in L. digitata (Küpper et al. 2001) and in spermatophytes (Auh and Murphy 1995, Doke and Miura 1995, Bolwell et al. 1998).

It is not known yet how plant NADPH oxidase is regulated, but increasing evidence (Blume et al. 2000, Navazio et al. 2002) indicates that a signal transduction cascade, including protein kinases, protein phosphatases, ion channels, changes in membrane potential, permeability, and ion fluxes, is involved (Wojtaszek 1997). This evidence is mainly based on pharmacological investigations conducted with known chemical inhibitors of mammalian enzymes. The same approach has also widely been used to distinguish between sources of ROS in the oxidative burst (Levine et al. 1994, Auh and Murphy 1995, Bolwell et al. 1998, Martinez et al. 1998). The specificity of chemical enzyme inhibitors is in most cases limited and dose dependent. For example, at relatively low concentrations diphenylene-iodonium (DPI) irreversibly binds to the flavonoid group of the NADPH oxidase complex (O'Donnell et al. 1993), whereas high concentrations of DPI also affect other enzymes potentially involved in the generation of ROS (Bolwell 1999).

In contrast with the ubiquitous response of higher plant cells upon challenge with either oligogalacturonans or oligoglucans, the capacity to recognize a specific oligosaccharide seems to be confined to some algal taxa. In six species of the Gracilariaceae that were test- ed, all responded with a respiratory burst when they were challenged with agar oligosaccharides (Weinberger et al. 1999). In contrast, such responses were not observed when other red algae, agarophytes or not, were examined. Sensitivity to agar oligosaccharides therefore seemed to be a ubiquitous but specific feature in the Gracilariaceae. However, the respective sources of ROS production were not clearly determined in these previous reports.

It was the purpose of the present study to identify the source of $\mathrm{H}_{2} \mathrm{O}_{2}$ that is activated in $G$. conferta after elicitation with agar oligosaccharides and to verify whether Gracilaria chilensis C. J. Bird, McLachlan \& E. C. Oliveira responds in an analogous way. A system with similar pharmacological sensitivities as the receptor-activated NADPH oxidase in spermatophytes is shown to respond to agar oligosaccharides in G. conferta. Gracilaria chilensis, in contrast, contains an oxidase specific for agar oligosaccharides. Using for the first time cerium perhydroxide precipitation for the subcellular localization of ROS generation in seaweeds, we show that $\mathrm{H}_{2} \mathrm{O}_{2}$ generation is apoplastic in G. chilensis but plasma membrane located in G. conferta.

\section{MATERIALS AND METHODS}

Plant material and cultivation procedures. Gracilaria chilensis C. J. Bird, McLachlan \& E. C. Oliveira originated from Caldera, IIIrd region of Chile. The isolates used were CR14, CR16, and CS7. Further isolates from Caldera, as well as from La Herradura and Praia Changas (IVth region), were also used for PAGE, whereas strain CUA was collected at Curaco (Xth region). Gracilaria chilensis and G. conferta (Schousboe ex Montagne) Montagne from Israel were cultivated in aerated tanks. The water temperature was maintained with heat exchangers at $25^{\circ} \mathrm{C}$ in the case of G. conferta and at 12 to $17^{\circ} \mathrm{C}$ in the case of $G$. chilensis. Day length was $12 \mathrm{~h}$, and the photon flux density was $45 \mu \mathrm{mol}$ photons $\cdot \mathrm{m}^{-2} \cdot \mathrm{s}^{-1}$. During light exposure, a halogen lamp provided $G$. conferta every hour for $30 \mathrm{~min}$ with additional $80 \mu \mathrm{M} \cdot \mathrm{m}^{-2} \cdot \mathrm{s}^{-1}$. The water was exchanged daily, and nitrate and phosphate were supplied by weekly pulse feeding. Shorttime incubations for elicitations and physiological assays were conducted in Petri dishes or Erlenmeyer flasks on shakers, using autoclaved seawater as medium. Algal fresh weight density was generally $50 \mathrm{mg} \cdot \mathrm{mL}^{-1}$, and the temperature during incubation was $13^{\circ} \mathrm{C}$ for $G$. chilensis and room temperature for G. conferta.

Chemicals and oligosaccharides. All chemicals and solvents were from Sigma (St. Quentin, France) and Merck (Darmstadt, Germany). Pharmacological agents were added from stock solutions prepared with DMSO or with water in the cases of potassium cyanide $(\mathrm{KCN})$, sodium azide $\left(\mathrm{NaN}_{3}\right)$, and 4 -aminopyridine. For the production of agar oligosaccharides, $\beta$-agarase from Zobellia galactanivorans was produced and used to degrade agarose (lot no. GC530223, Eurogentec, Seraing, Belgium) as described earlier (Allouch et al. 2003). Size calibrated neoagarobiose and neoagarotetraose and a fraction containing agar oligosaccharides consisting of more than four monosaccharide residues were prepared by gel filtration of the hydrolysate on a BioGel P-2 column (Bio-Rad, Hercules, CA, USA). Reduced agar oligosaccharides were prepared by incubation with sodium borohydride as described in Weinberger et al. (2001). All saccharides were added from stock solutions containing $10 \mathrm{mg} \cdot \mathrm{mL}^{-1}$ that were 
stored at $-20^{\circ} \mathrm{C}$. The molarities of stock solutions were calculated from the content of reducing saccharides.

$\mathrm{H}_{2} \mathrm{O}_{2}$ quantification. Hydrogen peroxide in the algal medium was quantified as luminol-dependent luminescence, using a Lumat LB 9507 luminometer (EG\&G Berthold, Bad Wildbad, Germany). A sample volume of $300 \mu \mathrm{L}$ was mixed with $100 \mu \mathrm{L}$ of a $0.3-\mathrm{mM}$ luminol solution and $50 \mu \mathrm{L}$ of phosphate buffer $(10 \mathrm{mM}, \mathrm{pH} 7.8)$ containing $20 \mathrm{U} \cdot \mathrm{mL}^{-1}$ horseradish peroxidase (Boehringer, Mannheim, Germany), and the luminescence was quantified immediately. In experiments requiring application of enzyme inhibitors, $250 \mu \mathrm{L}$ of a $13 \mathrm{mM}$ potassium ferricyanate solution was injected into the samples as catalyst instead of peroxidase (Bolwell et al. 1998), and seawater buffered with 4-(2-hydroxyethyl)piperazine1-ethanesulfonic acid ( $\mathrm{pH} 7.6,50 \mathrm{mM}$ ) was used as medium. Under such conditions, only KCN interfered with the assay and increased its sensitivity in a dose-dependent manner by up to 16.5 times. Results obtained with KCN were corrected accordingly. In dose-response experiments, $\mathrm{H}_{2} \mathrm{O}_{2}$ concentrations were quantified $30 \mathrm{~min}$ after addition of agar oligosaccharides to the medium of $G$. chilensis. In analogous experiments with $G$. conferta, four $\mathrm{H}_{2} \mathrm{O}_{2}$ measurements were conducted 2.5, 3, 3.5, and 4 min after exposure of G. conferta to agar oligosaccharides, and the mean of the four data obtained was calculated. Data obtained in dose-response experiments were fitted by iterative adaptation to logistic or Michaelis-Menten functions. In addition to the treatments (a), three different controls were run in all experiments to allow for compensation of $\mathrm{H}_{2} \mathrm{O}_{2}$ scavenging and $\mathrm{H}_{2} \mathrm{O}_{2}$ release due to uncontrolled effects. These were (b) medi$\mathrm{um}+$ treatment, (c) medium + alga, and (d) medium only. The net-release of $\mathrm{H}_{2} \mathrm{O}_{2}$ was then calculated according to the formula $((a-b)-(c-d)) \times(\text { algal density })^{-1}=$ release. For the determination of $\mathrm{H}_{2} \mathrm{O}_{2}$ scavenging potentials, approximately $15 \mu \mathrm{M} \mathrm{H}_{2} \mathrm{O}_{2}$ were added to the medium of Gracilaria and the decrease of $\mathrm{H}_{2} \mathrm{O}_{2}$ concentrations in the medium was followed during $40 \mathrm{~min}$.

Subcellular localization of $\mathrm{H}_{2} \mathrm{O}_{2}$. The cytochemical method for localization of $\mathrm{H}_{2} \mathrm{O}_{2}$ was based on the generation of insoluble cerium peroxides and adapted from Bestwick et al. (1997). After inoculation with or without agar oligosaccharides for various time periods, Gracilaria pieces $(2-4 \mathrm{~mm})$ were incubated in culture medium containing $5 \mathrm{mM}$ cerium chloride and $50 \mathrm{mM} 3$-(morpholino) propanesulfonic acid (pH 7.2) for $1 \mathrm{~h}$. Smaller Gracilaria pieces $(0.5-1 \mathrm{~mm})$ were then excised and fixed in 3\% (v/v) glutaraldehyde in $0.1 \mathrm{M}$ sodium cacodylate buffer ( $\mathrm{pH} 7.2$ ) containing $0.25 \mathrm{M}$ sucrose for $1 \mathrm{~h}$. The samples were then transferred to a similar fixing solution containing $1.5 \%$ paraformaldehyde. Fixation was followed by a series of rinses in $0.1 \mathrm{M}$ sodium cacodylate buffer containing sucrose. The original sucrose concentration was reduced by $25 \%$ in each successive step. After two rinses in pure buffer, the specimens were postfixed for $2 \mathrm{~h}$ in $0.1 \mathrm{M}$ sodium cacodylate buffer containing $2 \%$ osmium tetroxide. Samples were then dehydrated in acetone, infiltrated over 4 days, and embedded in Spurr's resin. Sections were examined using a 100 CXII electron microscope (Jeol Inc., Peabody, MA, USA) without staining with uranyl acetate or lead citrate.

PAGE of agar oligosaccharide oxidase. Algal samples were ground in liquid nitrogen and incubated at $4^{\circ} \mathrm{C}$ for $60 \mathrm{~min}$ in $1 \mathrm{~mL} \cdot \mathrm{g}^{-1}$ of extraction buffer $(50 \mathrm{mM}$ Tris- $\mathrm{HCl}, \mathrm{pH} 9.5$, $500 \mathrm{mM}$ potassium chloride, and $10 \mathrm{mM} \beta$-mercaptoethanol). Protein extracts were assayed for protein concentrations (Bradford 1976) and separated $(50 \mu \mathrm{g}$ of total protein per lane) by PAGE (Laemmli, 1970) on 12\% acrylamide gels, using a buffer system free of SDS. For staining of agar oligosaccharide oxidase, a method for the detection of glucose oxidase (Cavener 1980) was adapted. The gels were incubated for $3.5 \mathrm{~h}$ in a shaker at room temperature in phosphate buffer $(0.1 \mathrm{M}, \mathrm{pH} 7.6)$ containing $0.16 \mathrm{mM}$ phenazine methosulfate and $0.24 \mathrm{mM}$ (3-[4,5-dimethylthiazol-2-yl]-2,5diphenyltetrazolium bromide (MTT). Agar oligosaccharide substrate was added to the mixture at $10 \mathrm{mM}$. Stained gels were scanned, and the relative staining intensity of bands on digitalized images was quantified using the free Image J software (National Institutes of Health, Bethesda, MD, USA), available from the public domain at http://rsb.info.nih.gov/ij/.

Spectrophotometric assays. Spectrophotometric methods were used for the quantification of reducing saccharides (Kidby and Davidson 1973), total carbohydrates (Tillmans and Philippi 1929, modified by Rimington 1931), carbonyl compounds (Paz et al. 1965), uronic acids (Blumenkrantz and Asboe-Hansen 1973), and aldehydes (Sawicki et al. 1961) in algal medium. An adaptation of the assay of Sawicki et al. (1961) was also used for the determination of agar oligosaccharide oxidase activity potentials in protein crude extracts. Aliquots of protein extract $(10 \mu \mathrm{L})$ were incubated in reaction tubes in a shaker at $25^{\circ} \mathrm{C}$ with $10 \mu \mathrm{L}$ of 4 -(2-hydroxyethyl)piperazine-1-ethanesulfonic acid buffer $(0.1 \mathrm{M}$, $\mathrm{pH} 7.6)$ and $80 \mu \mathrm{L}$ agar oligosaccharide substrate $(13 \mathrm{mM})$. Sample tubes were conserved at $-80^{\circ} \mathrm{C}$ after defined incubation intervals. After completion of the incubation, $0.2 \mathrm{~mL}$ acetate buffer $(0.2 \mathrm{M}, \mathrm{pH} 4.0)$ and $0.2 \mathrm{~mL}$ of a $0.5 \%$ aqueous solution of 3-methyl-2-benzo-thiazolinone hydrazone were added to all tubes, and they were incubated for $3 \mathrm{~min}$ at $100^{\circ}$ C. After cooling to room temperature, $1.25 \mathrm{~mL}$ of a freshly prepared solution of iron (III) chloride $(0.2 \%)$ was added and the resulting tetraazopentamethine cyanine dye was quantified at $670 \mathrm{~nm}$, using galacturonic acid as standard.

\section{RESULTS}

Kinetics of $\mathrm{H}_{2} \mathrm{O}_{2}$ release in response to agar oligosaccharides differ in Gracilaria chilensis and Gracilaria conferta. Exposure to agar oligosaccharides resulted in an immediate release of $\mathrm{H}_{2} \mathrm{O}_{2}$ in both $G$. chilensis and $G$. conferta yet with markedly different kinetics (Fig. 1). In G. chilensis, maximal $\mathrm{H}_{2} \mathrm{O}_{2}$ concentrations were typically observed from 20 to $30 \mathrm{~min}$ after the addition of $300 \mu \mathrm{M}$ agar oligosaccharides to the incubation medium, and they remained stable for more than $30 \mathrm{~min}$. Transfer of $G$. chilensis into a fresh me-

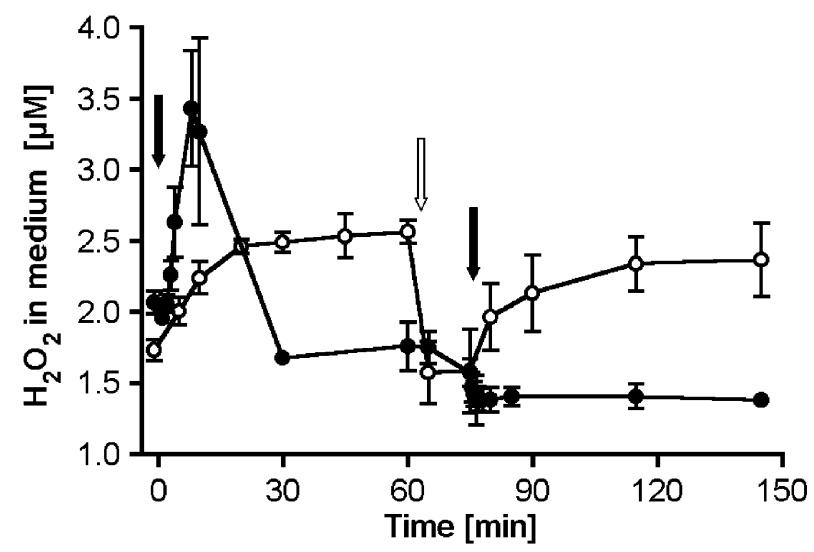

FIG. 1. Kinetics of $\mathrm{H}_{2} \mathrm{O}_{2}$ concentrations in the medium of Gracilaria chilensis ( ० ) and G. conferta $(\bullet)$ during two cycles of exposure to agar oligosaccharides (black arrows) upon replacement of the medium with fresh medium (white arrow). 
TABLE 1. Effects of pharmacological agents on $\mathrm{H}_{2} \mathrm{O}_{2}$ release by Gracilaria chilensis and $G$. conferta after challenge with agar oligosaccharides.

\begin{tabular}{|c|c|c|c|c|}
\hline \multirow[b]{2}{*}{ Reagent } & \multicolumn{2}{|c|}{ G. chilensis } & \multicolumn{2}{|c|}{ G. conferta } \\
\hline & Effect & $\mathrm{EC}_{50}$ or dose tested $(\mu \mathrm{M})$ & Effect & $\mathrm{EC}_{50}$ or dose tested $(\mu \mathrm{M})$ \\
\hline Chlorpromazine & Full inhibition & $20(10.7-37.5)$ & Full inhibition & $18(7.8-41.2)$ \\
\hline Quinacrine & Full inhibition & $41.2(17.7-95.9)$ & Full inhibition & $22.8(13.6-38.3)$ \\
\hline DPI & No & 100 & Full inhibition & $0.15(0.079-0.285)$ \\
\hline SHAM & Full inhibition & $14.2(5.2-38.5)$ & No & 100 \\
\hline KCN & Full inhibition & $959(796-1155)$ & $220 \%$ increase & $421(208-850)$ \\
\hline $\mathrm{NaN}_{3}$ & Full inhibition & $758(310-1854)$ & $1300 \%$ increase & $87.4(65.7-116.3)$ \\
\hline Staurosporine & No & 100 & Full inhibition & 73.7 (35.7-132.0) \\
\hline Cantharidine & No & 100 & $200 \%$ increase & $60-200$ \\
\hline Bepridil & No & 100 & Full inhibition & $1.5(0.2-10.2)$ \\
\hline Verapamil & No & 100 & Full inhibition & $46.2(31.9-66.9)$ \\
\hline A23187 & No & 100 & $150 \%$ increase & 100 \\
\hline 4-Aminopyridine & No & 1000 & Full inhibition & 999 (519-1922) \\
\hline
\end{tabular}

The incubation times after exposure to agar oligosaccharides were $45 \mathrm{~min}$ and $4 \mathrm{~min}$ for G. chilensis and G. conferta, respectively. Either the tested doses or the necessary doses for half maximal $\left(\mathrm{EC}_{50}\right)$ inhibition (with $95 \%$ confidence intervals in brackets) are given.

dium followed by addition of agar oligosaccharides immediately resulted in a renewed release of $\mathrm{H}_{2} \mathrm{O}_{2}$. With G. conferta, maximal concentrations of $\mathrm{H}_{2} \mathrm{O}_{2}$ in the medium were reached less than 10 min after the addition of $30 \mu \mathrm{M}$ agar oligosaccharides. In this alga, however, a desensitizing effect was apparent and resulted in a single oxidative burst after the first elicitation. Subsequent challenge with $30 \mu \mathrm{M}$ agar oligosaccharides did not trigger the same response.

In $G$. chilensis and in G. conferta, no $\mathrm{H}_{2} \mathrm{O}_{2}$ accumulation was detected after exposure to agar oligosaccharides when $1000 \mathrm{U} \cdot \mathrm{mL}^{-1}$ catalase was added to the medium (data not shown). The responses of the two species were differently affected by the $\mathrm{pH}$ of the medium. In G. chilensis, a maximal release was observed at pH 7.8-8.5, whereas G. conferta maximally responded at $\mathrm{pH} 7.0$ (data not shown).

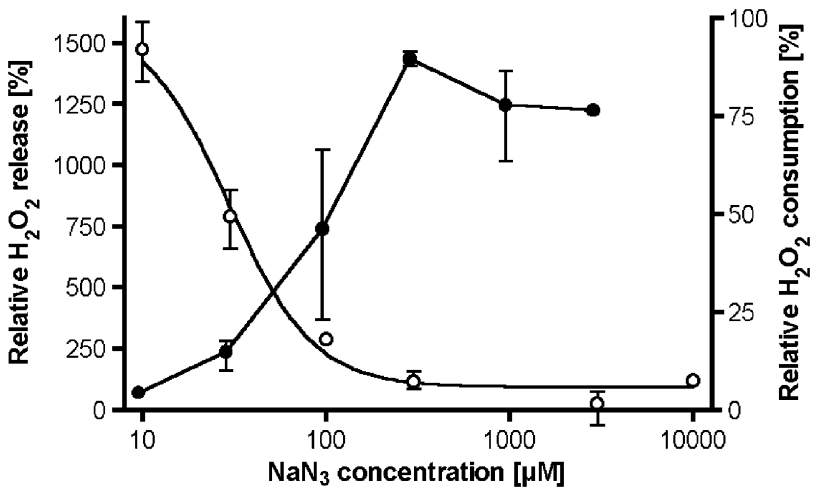

FIG. 2. Effect of $\mathrm{NaN}_{3}$ on $\mathrm{H}_{2} \mathrm{O}_{2}$ scavenging and on the agar oligosaccharide-induced release of $\mathrm{H}_{2} \mathrm{O}_{2}$ by Gracilaria conferta. For measurement of (o) $\mathrm{H}_{2} \mathrm{O}_{2}$ scavenging, $15 \mu \mathrm{M} \mathrm{H} \mathrm{H}_{2} \mathrm{O}_{2}$ were externally applied and the rate of decomposition during $40 \mathrm{~min}$ was measured. The line represents a best fitting logistic function. For $(\bullet)$ induction of $\mathrm{H}_{2} \mathrm{O}_{2}$ release, agar oligosaccharide was added to the medium at $30 \mu \mathrm{M}$. Responses in absence of azide were regarded as $100 \%$, and bars indicate minimal and maximal responses.
Inhibitor studies. Of 18 pharmacological agents that were tested, only chlorpromazine, quinacrine, salicylhydroxamic acid (SHAM), KCN, and $\mathrm{NaN}_{3}$ inhibited the release of $\mathrm{H}_{2} \mathrm{O}_{2}$ in $G$. chilensis (Table 1). In contrast, the response of $G$. conferta was uninhibited by SHAM, KCN, and $\mathrm{NaN}_{3}$ but sensitive to a wide range of other compounds (Table 1): The oxidative burst was inhibited by chlorpromazine and quinacrine and was particularly sensitive to DPI. Staurosporine, a general inhibitor of protein kinases, reduced the $\mathrm{H}_{2} \mathrm{O}_{2}$ release by $50 \%$ at $73.7 \mu \mathrm{M}$, whereas the protein phosphatase inhibitor cantharidine approxi-

FIG. 4. Localization of $\mathrm{H}_{2} \mathrm{O}_{2}$ production in Gracilaria chilensis (A-C) and G. conferta (D-G) upon exposure to agar oligosaccharides. (A) General view of a $G$. chilensis epidermal cell. Four chloroplasts occupy most of the cell in this section. The cell wall is composed of an outer and an inner stratum. Gradual electron-dense deposits of cerium perhydroxide are present in the inner and outer cell wall (arrowheads). The alga was fixed $60 \mathrm{~min}$ after exposure to $100 \mu \mathrm{M}$ agar oligosaccharide. (B) Detail of an apical portion of a $G$. chilensis epidermal cell showing electrondense deposits of cerium perhydroxide at the outer edge of the cell wall $70 \mathrm{~min}$ after exposure to agar oligosaccharides. (C) Gracilaria chilensis epidermal cell (control). (D) General view of G. conferta epidermal cells. Numerous chloroplasts and the nucleus can be seen in this section. The cell wall also is composed of an outer and an inner stratum. Small electron-dense deposits of cerium perhydroxide are present only in the vicinity of the cell membrane (arrowheads). The alga was fixed after $1 \mathrm{~min}$ of exposure to $30 \mu \mathrm{M}$ agar oligosaccharides. (E) Detail of a $G$. conferta epidermal cell showing the small electron-dense deposits of cerium perhydroxide localized at the cell membrane (arrowheads). (F) View of a portion of two contiguous $G$. conferta cortical cells joined by a pit connection. A vacuole, endoplasmic reticulum, chloroplasts, and floridean starch granules can be seen in this section. A clear increase of electron-dense deposit of cerium perhydroxide can be seen at the cell membrane (arrowheads). The alga was fixed after $7 \mathrm{~min}$ of exposure to $30 \mu \mathrm{M}$ agar oligosaccharides. (G) Gracilaria conferta cortical cells (control). c, chloroplast; er, endoplasmic reticulum; iw, inner wall; $m$, mitochondrium; ow, outer wall; $\mathrm{p}$, pit connection; s, floridean starch granule; $v$, vacuole; w, wall. Scale bars: A, C, and D, $1 \mu \mathrm{m}$; B, $2 \mu \mathrm{m}$; E, $0.25 \mu \mathrm{m}$; $\mathrm{F}$ and $\mathrm{G}, 0.5 \mu \mathrm{m}$. 


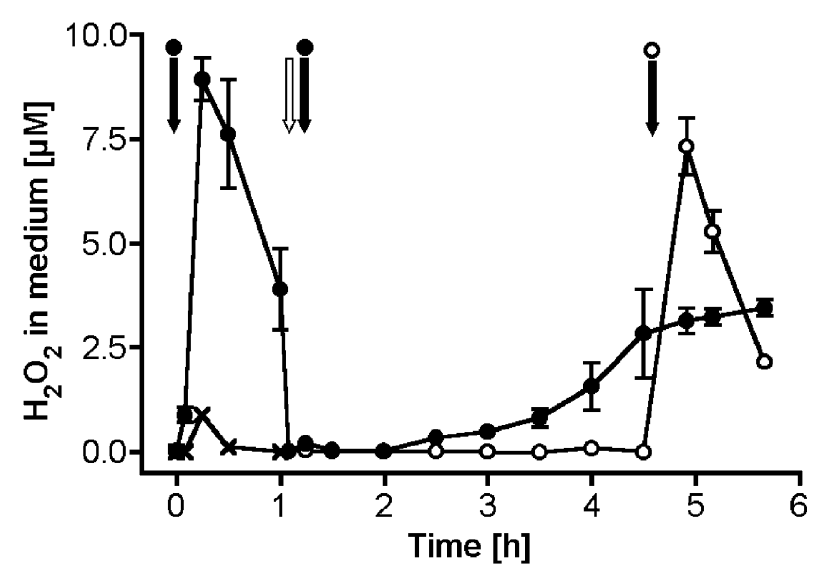

FIG. 3. Recovery from the refractory state after agar oligosaccharide elicitation in Gracilaria conferta. The algae were incubated in presence of $100 \mu \mathrm{M} \mathrm{NaN}$ to suppress $\mathrm{H}_{2} \mathrm{O}_{2}$ scavenging. Agar oligosaccharides at $300 \mu \mathrm{M}$ were added (black arrow, $\bullet, \circ)$ or not added $(x)$ in the beginning. After $1 \mathrm{~h}$, unelicited plants $(x)$ were discarded, and the medium of elicited plants was replaced with fresh medium (white arrow). Agar oligosaccharides at $300 \mu \mathrm{M}$ were applied a second time after 65 min (black arrow, • ) or after $4.5 \mathrm{~h}$ (black arrow, ○). Bars indicate $\pm \mathrm{SD}, n=3$. mately doubled it when it was present at similar concentrations. Bepridil and verapamil, as well as other blockers of calcium channels (flunarizine and diltiazem, data not shown), generally inhibited the release of $\mathrm{H}_{2} \mathrm{O}_{2}$. A certain inhibition was also observed with ophiobolin $\mathrm{A}$, an inhibitor of the calmodulin system, and the calcium ionophore A23187 increased the response. A full inhibition was observed when relatively high concentrations of the potassium channel inhibitor 4-aminopyridine were applied.

Presence of $\mathrm{NaN}_{3}$ or KCN in the medium of G. conferta increased the release of $\mathrm{H}_{2} \mathrm{O}_{2}$ after challenge with agar oligosaccharide (Table 1), and this increase was correlated with a decrease in the algal capacity to scavenge $\mathrm{H}_{2} \mathrm{O}_{2}$ (Fig. 2). Application of $100 \mu \mathrm{M} \mathrm{NaN}$ still inhibited most $\mathrm{H}_{2} \mathrm{O}_{2}$ scavenging in G. conferta and thus allowed a more sensitive detection of $\mathrm{H}_{2} \mathrm{O}_{2}$ release. It was in this way possible to demonstrate that the recovery of $G$. conferta from the refractory state began $2.5 \mathrm{~h}$ after exposure to agar oligosaccharide, because G. conferta began at that time with a new release of $\mathrm{H}_{2} \mathrm{O}_{2}$ when agar oligosaccharide was present in its medium (Fig. 3). As with the first response (Table 1), this new $\mathrm{H}_{2} \mathrm{O}_{2}$ release was sensitive to $10 \mu \mathrm{M}$ DPI and uninhib-

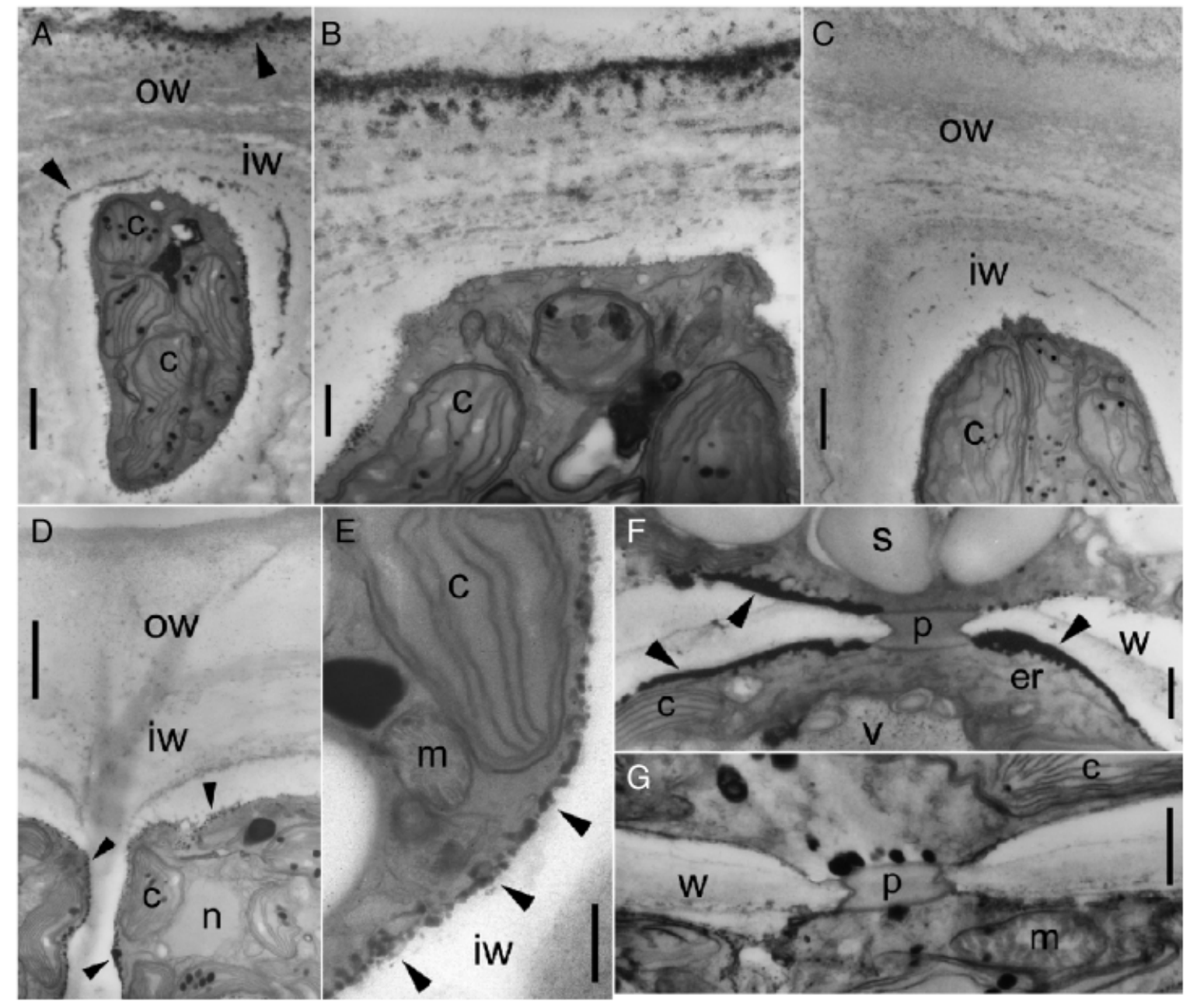


TABle 2. Kinetic constants for $\mathrm{H}_{2} \mathrm{O}_{2}$ release by Gracilaria chilensis after exposure to agar oligosaccharides with three different degrees of neoagarobiose polymerization.

\begin{tabular}{lcccc}
\hline \hline Degree of neoagarobiose polymerization & $\mathrm{V}_{\max }\left(\mathrm{nmol} \cdot \mathrm{g}^{-1} \cdot \mathrm{min}^{-1}\right)$ & $95 \%$ confidence interval & $\mathrm{K}_{\mathrm{m}}(\mu \mathrm{M})$ & $95 \%$ confidence interval \\
\hline 1 & No response & 2.3 & - & - \\
2 & 1.2 & $2.0-2.6$ & 138.8 & $102.3-175.4$ \\
$>2$ & $1.0-1.3$ & 33.1 & $14.8-51.4$ \\
\hline
\end{tabular}

The maximal responses $\left(\mathrm{V}_{\max }\right)$ and the necessary doses for induction of half maximal responses $\left(\mathrm{K}_{\mathrm{m}}\right)$ are given with their $95 \%$ confidence intervals.

ited by $200 \mu \mathrm{M}$ SHAM and $10 \mathrm{mM} \mathrm{NaN}_{3}$ (data not shown). The capability of $G$. conferta to respond with an oxidative burst to agar oligosaccharide was nearly fully restored after $5 \mathrm{~h}$ (Fig. 3).

Sites of $\mathrm{H}_{2} \mathrm{O}_{2}$ production in response to agar oligosaccharides. When G. chilensis was incubated in the presence of both cerium chloride and agar oligosaccharides, several layers of electron-dense material appeared in the cell wall (Fig. 4, A and B), accumulating at the outer cell wall. This cerium perhydroxide precipitate became visible after 30 to 70 min of exposure to the agar oligosaccharides. Cerium perhydroxide did not precipitate when no agar oligosaccharides had been added to the medium (Fig. 4C). In G. conferta, electron-dense material was visibly accumulated at the plasma membrane as early as $1 \mathrm{~min}$ after agar oligosaccharides had been added to the medium (Fig. 4, D and E). After 7 min, dense layers of cerium perhydroxide deposits were observed at the plasma membrane, not only in the epidermal cells but also in the second layer of cortical cells (Fig. 4F). Precipitates of cerium perhydroxide were not observed in the controls (Fig. 4G).

Gracilaria chilensis displays an agar oligosaccharide oxidase activity. No release of $\mathrm{H}_{2} \mathrm{O}_{2}$ by G. chilensis was observed during incubation with oligosaccharides prepared from carrageenans, fucan, alginates, ulvan, pectins, chitins, or cellulose (data not shown). Neoagarobiose did not induce $\mathrm{H}_{2} \mathrm{O}_{2}$ release in G. chilensis, even when it was present at concentrations as high as $1 \mathrm{mM}$. The response to the presence of agar oligosaccharides larger than neoagarobiose was dose dependent, with a higher maximal response and consequently a higher $\mathrm{K}_{\mathrm{m}}$ toward neoagarotetraose than toward larger agar oligosaccharides (Table 2). The highest responses were observed when agar oligosaccharides were present in the medium at concentrations of $300 \mu \mathrm{M}$ or higher.

After reduction with sodium borohydrite, agar oligosaccharides did not induce release of $\mathrm{H}_{2} \mathrm{O}_{2}$ in G. chilensis at concentrations as high as $1 \mathrm{mM}$. Moreover, the application of $1 \mathrm{mM}$ of reduced agar oligosaccharides in combination with $130 \mu \mathrm{M}$ of nonreduced agar oligosaccharides resulted in a slower release of $\mathrm{H}_{2} \mathrm{O}_{2}$ compared with the application of $130 \mu \mathrm{M}$ agar oligosaccharides alone (Fig. 5).

Development of native PAGE gels loaded with G. chilensis protein extracts in the presence of phenazine methosulfate and MTT revealed five additional bands (1-5, Fig. 6) when agar oligosaccharides were present in the incubation buffer. No additional bands developed in $G$. conferta in the presence of agar oligosaccharides (data not shown). None of the bands observed with $G$. chilensis was detected when the development of PAGE gels was conducted in the presence of quinacrine, chlorpromazine, or SHAM or when agar oligosaccharides were replaced with D-galactose. Bands 1 to 3 were detected in extracts from all 15 G. chilensis individuals that were examined, whereas bands 4 and 5 were only detected in extracts from strain CUA. The staining intensity of bands 1 to 3 did not differ significantly between the 15 different strains due to a generally high variability over time in all strains (data not shown). This variability resulted in part from variations in the temperature regime during cultivation: Incubation of $G$. chilensis for 6 or more weeks at $16^{\circ} \mathrm{C}$ resulted in a staining intensity of lanes 1 to 5 that was nearly seven times as high as after incubation for 10 weeks at $12^{\circ} \mathrm{C}$ (Fig. 7).

An enrichment in carbonylic and aldehydic compounds, but not in uronic acids, was observed when G. chilensis was incubated in the presence of agar oligosaccharides (Fig. 8). The molar ratios of carbonyl compounds and aldehydes to the agar oligosaccharides initially applied were approximately $0.85: 1$. In contrast, only about $0.1 \mathrm{~mol}$ of carbonyl compounds and aldehydes were generated per mol of agar oligosaccharides previously reduced with sodium borohydrite.

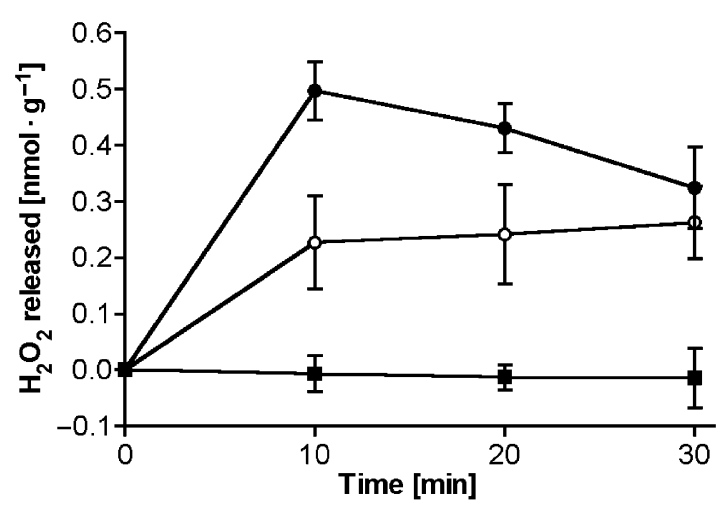

FIg. 5. Release of $\mathrm{H}_{2} \mathrm{O}_{2}$ by Gracilaria chilensis after exposure to $130 \mu \mathrm{M}$ agar oligosaccharides $(\bullet), 1 \mathrm{mM}$ reduced agar oligosaccharides $(\times)$, and $130 \mu \mathrm{M}$ agar oligosaccharides in combination with $1 \mathrm{mM}$ reduced agar oligosaccharides $(\circ)$. Bars indicate $\pm \mathrm{SD}, n=5$. 


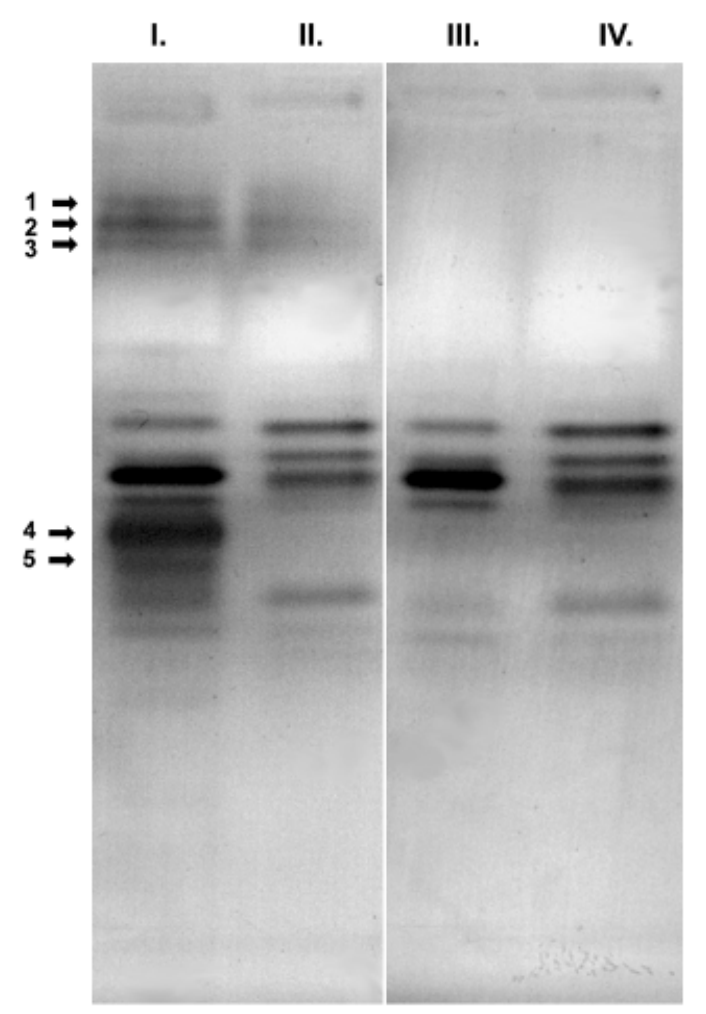

FIG. 6. Expression of agar oligosaccharide oxidase in Gracilaria chilensis. The enzyme activity was revealed after native PAGE with addition of $10 \mathrm{mM}$ agar oligosaccharides. The same protein extracts are shown in lanes I and III (strain CUA) and in lanes II and IV (strain CR14), with (lanes I and II) and without the presence of agar oligosaccharides during the gel staining procedure. Arrows indicate the agar oligosaccharide oxidase isoforms.

Aldehydic compounds were also generated when agar oligosaccharide was added to crude protein extracts of G. chilensis. Production at a constant rate was

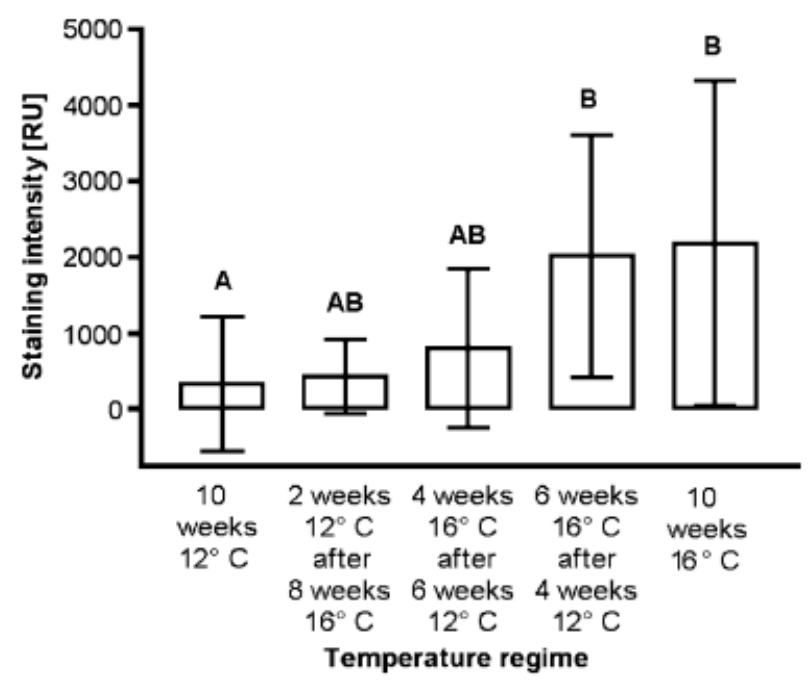

FIG. 7. Average total staining intensity of bands 1 to 5 as affected by the temperature regime during 10 weeks of Gracilaria chilensis cultivation before protein extraction. The sample size was $n=6$ to 18 ; bars indicate SD. Results marked with different letters are significantly different at $P<0.05$ in a Tukey test.

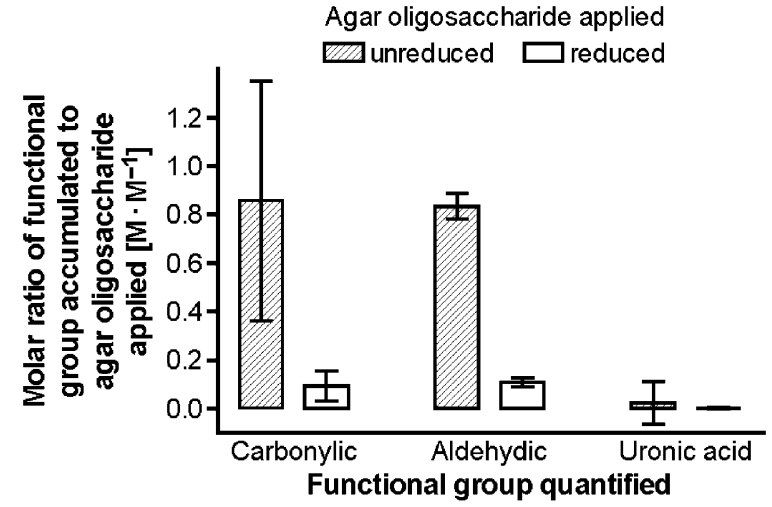

FIG. 8. Enrichment in saccharide functional groups of the culture medium of Gracilaria chilensis after the application of agar oligosaccharides $(300 \mu \mathrm{M})$ or of reduced agar oligosaccharides ( $1 \mathrm{mM})$. The amounts of carbonyl compounds, aldehydes, and uronic acids were quantified after $7 \mathrm{~h}$ of incubation. Error bars indicate $\pm \mathrm{SD}, n=5$.

typically observed during $2 \mathrm{~h}$ after the addition, whereas longer incubation periods usually resulted in reduced activity (Fig. 9A). A decrease in the aldehyde concentration after an initial increase was observed with some protein extracts, indicating that they contained components that decomposed the reaction product. Extracts that showed such interference were systematically excluded from the evaluation. Protein extracts that generated aldehyde at a relatively high rate generally also resulted in a strong agar oligosaccharide oxidase staining in native PAGE (Fig. 9B).

\section{DISCUSSION}

We show that the two species of Gracilaria under investigation responded with a release of $\mathrm{H}_{2} \mathrm{O}_{2}$ that was sensitive to catalase when agar oligosaccharides were applied to their culture medium. However, all the evidence we gathered indicates that two distinct cellular mechanisms are responsible for the release of extracellular $\mathrm{H}_{2} \mathrm{O}_{2}$, leading to different consequences in the defensive capabilities of these species.

Agar oligosaccharides are perceived as a signal by Gracilaria conferta. In G. conferta, a transient peak of $\mathrm{H}_{2} \mathrm{O}_{2}$ in the medium was observed for some minutes after the application of agar oligosaccharide, and this response could not be reinduced by supplying fresh medium and new agar oligosaccharides. The effect could be reverted only several hours after the first oxidative burst and the capacity to respond regenerated successively, indicating that the algal system of $\mathrm{H}_{2} \mathrm{O}_{2}$ production was in a refractory state as it is typically the case after recognition of chemical signals that activate phosphorylation events (Felix et al. 1993, Navazio et al. 2002). This view is further supported by the fact that the protein kinase inhibitor staurosporine inhibited the $\mathrm{H}_{2} \mathrm{O}_{2}$ release by G. conferta, whereas the protein phosphatase inhibitor cantharidine increased it. A complete reinduction of 

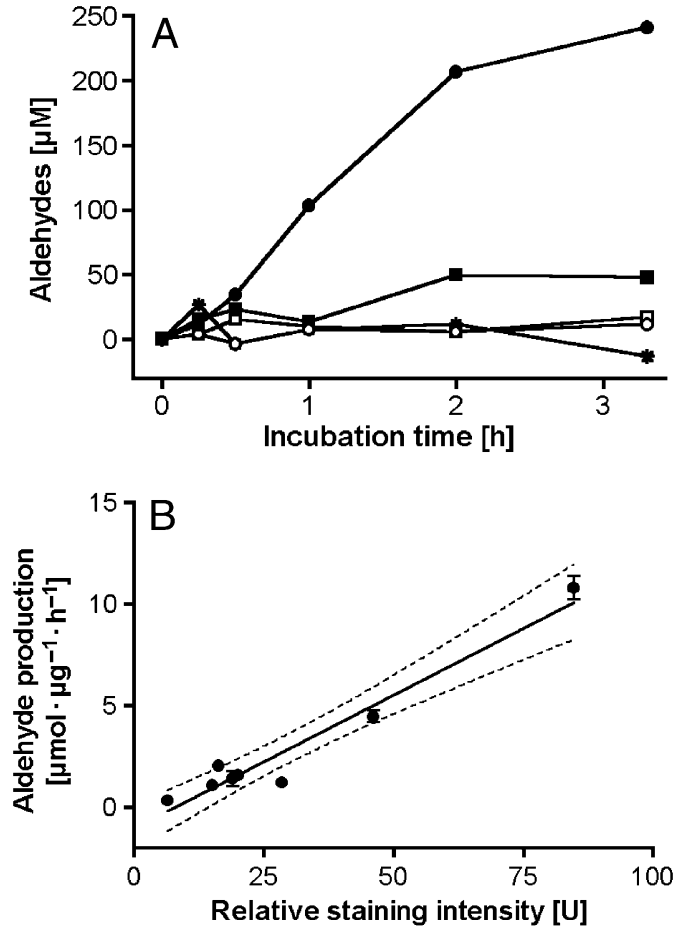

FIG. 9. Quantification of agar oligosaccharide oxidase activity potential in crude protein extracts from two different strains of Gracilaria chilensis. (A) During $2 \mathrm{~h}$ of incubation with agar oligosaccharide substrate, two extracts from strains CUA (•) and CR14 ( $)$ generated at approximately constant rates $10.8 \pm 0.5$ and $1.4 \pm 0.4 \mu \mathrm{M}$ aldehyde per $\mathrm{h}$ and $\mu \mathrm{g}$ protein, respectively, before the activity leveled off. No such production was observed when the same extracts were tested without substrate $(\circ, \square)$ or when the substrate was tested without protein extract (*). (B) A linear correlation (Spearman $r^{2}=0.833$, significant at $P<0.0102)$ between agar oligosaccharide oxidation activity potential in crude protein extracts during $2 \mathrm{~h}$ and the intensity of agar oligosaccharide oxidase staining on native PAGE gels.

$\mathrm{H}_{2} \mathrm{O}_{2}$ release was possible only $6 \mathrm{~h}$ after the first challenge of $G$. conferta with agar oligosaccharide, indicating a new availability of unphosphorylated protein kinase substrate.

All the inhibitors of plasma membrane calcium channels that were tested (e.g. bepridil, verapamil) inhibited the release of $\mathrm{H}_{2} \mathrm{O}_{2}$ at relatively low concentrations, and an increased release was observed when the calcium ionophore A23187 was applied. An intracellular increase in the concentration of calcium ions is thus necessary in $G$. conferta to allow for oxygen activation after recognition of agar oligosaccharides, as in spermatophytes (Doke and Miura 1995, Navazio et al. 2002) and in brown seaweeds (Küpper et al. 2001) after chemosensory perception. Ophiobolin A also partially reduced the release of $\mathrm{H}_{2} \mathrm{O}_{2}$, indicating that the cytosolic release of calcium after elicitation is amplified by the calmodulin system (Hidaka and Ishikawa 1992). The inhibitor of potassium channels, 4-aminopyridine, prevented the response of $G$. conferta to agar oligosaccharides, suggesting that potassium channels also play an essential role in the process.
The release of ROS by $G$. conferta after recognition of agar oligosaccharides was clearly located at the plasma membrane and it was sensitive to DPI at sub-micromolar concentrations, suggesting that an NADPH oxidase is involved in the production of ROS in this species. This idea is further supported by the sensitivity of the oxidative burst response to quinacrine and chlorpromazine, which are known to inhibit flavoenzymes such as NADPH oxidase (Auh and Murphy 1995, Bellavite et al. 1983).

Apoplastic peroxidases are excluded as enzymatic source of ROS because the $\mathrm{H}_{2} \mathrm{O}_{2}$ release in $G$. conferta after elicitation with agar oligosaccharide was clearly not located in the cell wall and not inhibited by SHAM, $\mathrm{KCN}$, and $\mathrm{NaN}_{3}$. The two later compounds even increased the accumulation of $\mathrm{H}_{2} \mathrm{O}_{2}$ in the culture medium, probably due to their inhibitory effect on apoplastic haloperoxidases, which are of major importance for $\mathrm{H}_{2} \mathrm{O}_{2}$ scavenging in Gracilaria (Pedersén et al. 1996, Weinberger et al. 1999).

Agar oligosaccharides are oxidized by Gracilaria chilensis. In G. chilensis, repeated supply of agar oligosaccharides immediately resulted in production of $\mathrm{H}_{2} \mathrm{O}_{2}$. A refractory state was not observed in this species, suggesting that agar oligosaccharide played a role as a substrate for the production of $\mathrm{H}_{2} \mathrm{O}_{2}$ rather than a signal. This idea is further supported by our finding that the site for oxygen activation was the apoplasm and that proteins capable of transferring electrons from agar oligosaccharide upon the phenazine methosulfate-MTT system are present in G. chilensis. The $\mathrm{H}_{2} \mathrm{O}_{2}$ release response was relatively insensitive to pharmacological inhibitors. Chlorpromazine and quinacrine fully inhibited it, which points to a flavoenzyme-catalyzed reaction. A full inhibition was also observed after application of relatively low doses of SHAM, which is known to interfere with the mode of action of various metalloenzymes (O'Brien et al. 2000). KCN and $\mathrm{NaN}_{3}$, two wellknown inhibitors of heme and copper enzymes, also inhibited the response.

An enzymatic oxidation of agar oligosaccharide occurred, because aldehydes accumulated in the medium of $G$. chilensis when it was incubated in the presence of agar oligosaccharide. This accumulation was not correlated with an enrichment of carbohydrates and thus was not due to an excretion of aldehydes but to an oxidation of the agar oligosaccharide. Moreover, crude protein extracts of $G$. chilensis also generated aldehyde from agar oligosaccharide. Their activity was correlated with the intensity of agar oligosaccharide-dependent staining of native PAGE gels, indicating that both effects were due to the same enzyme.

Approximately $0.85 \mathrm{~mol}$ aldehyde was generated per mol of agar oligosaccharide during $7 \mathrm{~h}$ of incubation of G. chilensis, suggesting that every substrate molecule may only be oxidized in one specific position. This position is probably not the anomeric C-atom. An oxidation at the anomeric C-atom would result in immediate internal esterification and formation of 
aldonic acid lactone (Horton et al. 1983), and such lactones are not detected by the assays that were used in our study for the quantification of carbonyl compounds and aldehydes. The oxidation site may therefore rather be the C6 atom of one specific D-Gal residue, and the importance of a free reducing end for the reaction suggests that this residue may be located close to the anomeric C-atom. A definite identification of the oxidation product, however, will require its purification.

It follows that an oxidase is present in the cell wall of G. chilensis that transfers electrons from agar oligosaccharides larger than neoagarobiose (Table 2) to molecular oxygen, thereby generating $\mathrm{H}_{2} \mathrm{O}_{2}$ and oxidized agar oligosaccharides. The characteristics of this enzyme are reminiscent of galactose oxidase (EC 1.1.3.9). This copper enzyme acts on the $\mathrm{C} 6$ atom of D-galactose and 1,5-anhydrogalactitol, but it has a higher affinity to oligo- and polysaccharides that contain D-galactose at the nonreducing end than to monosaccharides (Avigad et al. 1962). However, the enzyme present in $G$. chilensis cannot be galactose oxidase, because it does not act on D-galactose and because 3,6-anhydrogalactose is located at the nonreducing end of $\beta$-agarase products. Also, saccharides without a free anomeric C-atom are suitable substrates of galactose oxidase (Avigad et al. 1962), whereas an inhibition by reduced agar oligosaccharides was observed in our study. We therefore suggest that G. chilensis features an agar oligosaccharide oxidase.

The biological role of this enzyme is currently under investigation in our laboratory. Only agar oligosaccharides larger than the disaccharide proved to be suitable substrates for agar oligosaccharide oxidase, and only agarase can generate these saccharides. There is no indication for a presence of agarase in Gracilaria or other agarophytes, which leaves cell wall macerating microorganisms as the only source. It is therefore reasonable to suspect a role of agar oligosaccharide oxidase in the defense of $G$. chilensis against agar hydrolysis.

The expression of agar oligosaccharide oxidase in G. chilensis is extremely variable, which is not only indicated by the results obtained through PAGE but also by electron microscopic observations. Distinct bands of cerium peroxide appear in the cell wall, which presumably represent "waves" of the enzyme that were excreted into the apoplast at different occasions. Interestingly, the expression of agar oligosaccharide oxidase proved to be elevated after cultivation at $16^{\circ} \mathrm{C}$, which is only few degrees below the upper temperature limit of $19^{\circ} \mathrm{C}$ that was tolerated by $G$. chilensis in our laboratory. Increasing water temperatures generally result in increasing number and activity of agar degrading bacteria in the sea (Rieper-Kirchner 1989). Agar oligosaccharide oxidase thus appears to be used under conditions that are both stressful to G. chilensis and favorable to cell wall degradation. A toxic effect of $\mathrm{H}_{2} \mathrm{O}_{2}$ generated by agar oligosaccharide oxidase upon components of the microflora associated with G. chile- nsis has not been detected in our study (data not shown). Aldoses are generally suitable substrates for glycosylation (Lehmann 1996), and it may therefore be that agar oligosaccharide oxidase provides the substrate for a reaction of this type (e.g. a mechanism resulting in increased cell wall cross-linking).

In conclusion, the overall results of our study reveal that closely related red algae have developed two distinct mechanisms for localized $\mathrm{H}_{2} \mathrm{O}_{2}$ generation in response to cell wall agar oligosaccharides. In one system, the involvement of a signal transduction cascade, which activates a NADPH oxidase-like enzyme, located at the plasma membrane, is required to generate extracellular $\mathrm{H}_{2} \mathrm{O}_{2}$. The ROS generated directly acts as a biocide (Weinberger and Friedlander 2000) and provides a co-substrate for the halogenation of volatile organic compounds by haloperoxidases (Pedersén et al. 1996, Weinberger et al. 1999) and, eventually, of products of lipid peroxidation (Bouarab et al. 2004), which are often viewed as biocidal or signal compounds (Potin et al. 2002). Further roles for the $\mathrm{H}_{2} \mathrm{O}_{2}$ generated in signal transduction and cell wall cross-linking cannot be excluded. In the other system, $\mathrm{H}_{2} \mathrm{O}_{2}$ is generated, without any involvement of the protoplast, by a cell wall-localized oligosaccharide oxidase, and it is probably the oxidized saccharide rather than the $\mathrm{H}_{2} \mathrm{O}_{2}$ generated that plays a role in defense. Gracilaria conferta and G. chilensis live under distinct ecological conditions and do also probably belong to distinct genera (Gurgel and Fredericq 2004). It will therefore be interesting to investigate whether the differences observed in their responses to agar oligosaccharides are an ecological or rather a phylogenetic trait.

This study was financed by the European Commission INCODEV Programme (contribution number 4 of the joint research effort INCO-EPIFIGHT ICA4-CT-2001-10021). We are grateful to Dr. Sylvain Faugeron (Santiago, Chile) who provided us with G. chilensis and to Dr. Michael Friedlander (Haifa, Israel) who provided us with G. conferta. We also thank Murielle Jam and Olivier Di Franco for help with the preparation and analysis of agar oligosaccharides and with luminol assays, respectively.

Aldington, S. \& Fry, S. C. 1993. Oligosaccharins. Adv. Bot. Res. 19:1-101.

Allouch, J., Jam, M., Helbert, W., Barbeyron, T., Kloareg, B., Henrissat, B. \& Czjzek, M. 2003. The three-dimensional structures of two $\beta$-agarases. J. Biol. Chem. 278:47171-80.

Apostol, L., Low, P. S., Heinstein, P., Stipanovitch, R. D. \& Altman, D. W. 1987. Inhibition of elicitor-induced phytoalexin formation in cotton and soybean cells by citrate. Plant. Physiol. 84:1276-80.

Auh, C.-K. \& Murphy, T. M. 1995. Plasma membrane redox enzyme is involved in the synthesis of $\mathrm{O}_{2}^{-}$and $\mathrm{H}_{2} \mathrm{O}_{2}$ by Phytophthora elicitor-stimulated rose cells. Plant. Physiol. 107:1241-7.

Avigad, G., Amaral, D., Asensio, C. \& Horecker, L. 1962. The D-galactose oxidase of Polyporus circinatus. J. Biol. Chem. 237:2736-43.

Bellavite, P., Serra, M. C., Davoli, A., Bannister, J. V. \& Rossi, F. 1983. The NADPH oxidase of guinea pig polymorphonuclear leucocytes. Properties of the deoxycholate extracted enzyme. Mol. Cell. Biochem. 52:17-25. 
Bestwick, C. S., Brown, I. R., Bennett, M. H. R. \& Mansfield, J. W. 1997. Localization of hydrogen peroxide accumulation during the hypersensitive reaction of lettuce cells to Pseudomonas syringae pv phaseolicola. Plant Cell 9:209-21.

Blume, B., Nürnberger, T., Nass, N. \& Scheel, D. 2000. Receptormediated increase in cytoplasmic free calcium required for activation of pathogen defense in parsley. Plant Cell 12: $1425-40$.

Blumenkrantz, N. \& Asboe-Hansen, G. 1973. New method for quantitative determination of uronic acids. Anal. Biochem. 54: 484-9.

Bolwell, G. P. 1999. Role of active oxygen species and NO in plant defense responses. Curr. Opin. Plant Biol. 2:287-94.

Bolwell, G. P., Davies, D. R., Gerrish, C., Auh, C.-K. \& Murphy, T. M. 1998. Comparative biochemistry of the oxidative burst produced by rose and and French bean cells reveals two distinct mechanisms. Plant Physiol. 116:1379-85.

Bouarab, K., Adas, F., Gaquerel, E., Kloareg, B., Salaün, J.-P. \& Potin, P. 2004. The innate immunity of a marine red alga involves oxylipins from both the eicosanoid and octadecanoid pathways. Plant Physiol. 135:1838-48.

Bouarab, K., Potin, P., Correa, J. \& Kloareg, B. 1999. Sulfated oligosaccharides mediate the interaction between a marine red alga and its green algal pathogenic endophyte. Plant Cell 11:1635-50.

Braam, J. 1999. If walls could talk. Curr. Opin. Plant Biol. 2:521-4.

Bradford, M. M. 1976. A rapid and sensitive method for the quantification of microgram quantities of protein utilizing the principles of protein-dye binding. Anal. Biochem. 72:248-54.

Cavener, D. R. 1980. Genetics of male-specific glucose oxidase and the identification of other unusual hexose enzymes in Drosophila melanogaster. Biochem. Genet. 18:929-37.

Custers, J. H. H. V., Harrison, S. J., Sela-Buurlage, M. B., van Deventer, E., Lageweg, W., Howe, P. W., van der Meijs, P. J., Ponstein, A. S., Simons, B. H., Melchers, L. S. \& Maarten, H. 2004. Isolation and characterization of a class of carbohydrate oxidases from higher plants, with a role in active defence. Plant J. 39:147-60.

Darvill, A., Augur, C., Bergmann, C., Carlson, R. W., Cheong, J.-J., Eberhard, S., Hahn, M. G., Lo, V.-M., Marfa, V. \& Meyer, B. 1992. Oligosaccharins-oligosaccharides that regulate growth, development and defense responses in plants. Glycobiology 2:181-9.

Doke, N. \& Miura, Y. 1995. In vitro activation of NADPH-dependent $\mathrm{O}_{2}^{-}$generating system in a plasma membrane-rich fraction of potato tuber tissues by treatment with an elicitor from Phytophtora infestans or with digitonin. Physiol. Mol. Plant Pathol. 46:17-28.

Felix, G., Regenass, M. \& Boller, T. 1993. Specific perception of subnanomolar concentrations of chitin fragments by tomato cells: induction of extracellular alkalinization, changes in protein phosphorylation, and establishment of a refractory state. Plant J. 4:307-16.

Gurgel, C. F. D. \& Fredericq, S. 2004. Systematics of the Gracilariaceae (Gracilariales, Rhodophyta): a critical assessment based on $r b c \mathrm{~L}$ sequence analysis. J. Phycol. 37:881-99.

Hidaka, H. \& Ishikawa, T. 1992. Molecular pharmacology of calmodulin pathways in the cell functions. Cell Calcium 13:6-7.

Horton, D., Wałasek, Z. \& Ekiel, I. 1983. Conformations of D-gluconic, D-mannonic and D-galactonic acids in solution, as determined by n.m.r. spectroscopy. Carbohydr. Res. 119:263-8.

John, M., Röhrig, H., Schmidt, J., Walden, R. \& Schell, J. 1997. Cell signalling by oligosaccharides. Trends Plant Sci. 2:111-5.

Kidby, D. K. \& Davidson, D. J. 1973. A convenient ferricyanide estimation of reducing sugars in the nanomolar range. Anal. Biochem. 55:321-5.

Küpper, F. C., Kloareg, B., Guern, J. \& Potin, P. 2001. Oligoguluronates elicit an oxidative burst in the brown algal kelp Laminaria digitata. Plant Physiol. 125:278-91.

Küpper, F. C., Müller, D. G., Peters, A. F., Kloareg, B. \& Potin, P. 2002. Oligoalginate recognition and oxidative burst play a key role in natural and induced resistance of sporophytes of Laminariales. J. Chem. Ecol. 28:2057-81.
Laloi, C., Apel, K. \& Danon, A. 2004. Reactive oxygen signalling: the latest news. Curr. Opin. Plant Biol. 7:323-8.

Lamb, C. \& Dixon, R. A. 1997. The oxidative burst in plant disease resistance. Annu. Rev. Plant Physiol. Plant Mol. Biol. 48: 251-75.

Laemmli, U. K. 1970. Cleavage of structural proteins during the assembly of the head of bacteriophage T4. Nature 227:680-5.

Lehmann, J. 1996. Kohlenhydrate. Georg Thieme Verlag, Stuttgart, Germany, $372 \mathrm{pp}$.

Levine, A., Tenhaken, R., Dixon, R. \& Lamb, C. 1994. $\mathrm{H}_{2} \mathrm{O}_{2}$ from the oxidative burst orchestrates the plant hypersensitive disease resistance response. Cell 79:583-93.

Martinez, C., Montillet, J. L., Bresson, E., Agnel, J. P., Dai, G. H., Daniel, J. F., Geiger, J. P. \& Nicole, M. 1998. Apoplastic peroxidase generates superoxide anions in cells of cotton cotyledons undergoing the hypersensitive reaction to Xanthomonas campestris pv. malvacearum Race 18. Mol. Plant Microbe Inter. 11:1038-47.

Navazio, L., Moscatiello, R., Bellincampi, D., Baldan, B., Meggio, F., Brini, M., Bowler, C. \& Mariani, P. 2002. The role of calcium in oligogalacturonide-activated signalling in soybean cells. Planta 215:596-605.

O'Brien, E. C. O., Farkas, E., Gil, M. J., Fitzgerald, D., Castineras, A. \& Nolan, K. B. 2000. Metal complexes of salicylhydroxamic acid. Crystal and molecular structure of $\left[\mathrm{Cu}(\text { phen })_{2}(\mathrm{Cl})\right]$ $\mathrm{Cl} \cdot \mathrm{H} 2 \mathrm{Sh} a$, a model for a peroxidase-inhibitor complex. J. Inorg. Biochem. 79:74-51.

O’Donnell, V., Tew, D. G., Jones, O. T. G. \& England, P. J. 1993. Studies on the inhibitory mechanism of iodonium compounds with special reference to neutrophil NADPH oxidase. Biochem. J. 290:41-9.

Orozco-Cárdenas, M. L., Narváez-Vásquez, J. \& Ryan, C. A. 2001. Hydrogen peroxide acts as a second messenger for the induction of defense genes in tomato plants in response to wounding, systemin, and methyl jasmonate. Plant Cell 13:179-91.

Paz, M. A., Blumenfeld, O. O., Rojkind, M., Henson, E., Furfine, C. \& Gallop, P. M. 1965. Determination of carbonyl compounds with N-methyl benzothiazolone hydrazone. Arch. Biochem. Biophys. 109:548-59.

Pedersén, M., Collén, J., Abrahamsson, K., Mtolera, M., Semesi, A. \& Garcia Reina, G. 1996. The ice-ice disease and oxidative stress of marine algae. In Björk, M., Semesi, A. K., Pedersén, M. \& Bergman, B. [Eds.] Proceedings of the 3-10 December 1995 Symposium on the Biology of Microalgae, Macroalgae and Seagrasses in the Western Indian Ocean. Ord \& Vetande, Uppsala, Sweden, pp. 11-24.

Potin, P., Bouarab, K., Salaün, J. P., Pohnert, G. \& Kloareg, B. 2002. Biotic interactions of marine algae. Curr. Opin. Plant Biol. 5:308-17.

Rea, G., Metoui, O., Infantino, A., Federico, R. \& Angelini, R. 2002. Copper amine oxidase expression in defence responses to wounding and Ascochyta rabiei invasion. Plant Physiol. 128: $865-75$.

Rieper-Kirchner, M. 1989. Microbial degradation of North Sea macroalgae: field and laboratory studies. Bot. Mar. 32:241-52.

Rimington, C. 1931. The carbohydrate complex of the serum proteins. II. Improved method for isolation and redetermination of structure. Isolation of glucosaminodimannose from proteins of ox blood. Biochem. J. 25:1062-71.

Sawicki, E., Hauser, T. R., Stanley, T. W. \& Elbert, W. 1961. The 3-methyl-2-benzothiazolonone hydrazone test. Anal. Chem. 33:93-6.

Tillmans, J. \& Philippi, J. 1929. Über den Gehalt der wichtigsten Protein-Nahrungsmittel an Kohlehydrat und über ein kolorimetrisches Verfahren zur quantitativen Bestimmung von stickstoffreiem Zucker in Eiweiss. Biochem. Z. 215:3640.

Vorwerk, S., Somerville, S. \& Somerville, C. 2004. The role of plant cell wall polysaccharide composition in disease resistance. Trends Plant Sci. 9:203-9.

Weinberger, F. \& Friedlander, M. 2000. Response of Gracilaria conferta (Rhodophyta) to agar oligosaccharides results in control of agar degrading epiphytes. J. Phycol. 36:1079-86. 
Weinberger, F., Friedlander, M. \& Hoppe, H.-G. 1999. Agar oligosaccharides elicit a physiological response in Gracilaria conferta (Rhodophyta). J. Phycol. 35:747-55.

Weinberger, F., Pohnert, G., Berndt, M.-L., Bouarab, K., Kloareg, B. \& Potin, P. 2005. Apoplastic oxidation of L-asparagine is involved in the control of the endophyte Acrochaete operculata by Chondrus crispus. J. Exp. Bot. 56:1317-26.

Weinberger, F., Pohnert, G., Kloareg, B. \& Potin, P. 2002. A signal released by an endophytic attacker acts as a substrate for a rapid defensive reaction of the red alga Chondrus crispus. Chem. Biol. Chem. 3:1260-3.
Weinberger, F., Richard, C., Kloareg, B., Kashman, Y., Hoppe, H.-G. \& Friedlander, M. 2001. Structure-activity relationships of agar oligosaccharide elicitors toward Gracilaria conferta (Rhodophyta). J. Phycol. 37:418-26.

Wojtaszek, P. 1997. Oxidative burst: an early plant response to pathogen infection. Biochem. J. 322:681-92.

Zhang, Z., Collinge, D. B. \& Thordal-Christensen, H. 1995. Germin-like oxalate oxidase, a $\mathrm{H}_{2} \mathrm{O}_{2}$-producing enzyme, accumulates in barley attacked by the powdery mildew fungus. Plant J. 8:139-45. 